\title{
Aggressiveness and Competitive Fitness of Phytophthora infestans Isolates Collected from Potato and Tomato in France
}

\author{
Lionel Lebreton, Jean-Marie Lucas, and Didier Andrivon
}

INRA Station de Pathologie Végétale, Domaine de la Motte, BP 29, F-35653 Le Rheu Cedex, France. Accepted for publication 3 April 1999.

ABSTRACT

\begin{abstract}
Lebreton, L., Lucas, J.-M., and Andrivon, D. 1999. Aggressiveness and competitive fitness of Phytophthora infestans isolates collected from potato and tomato in France. Phytopathology 89:679-686.

To test the hypothesis that host-related differences in the genotypic composition of populations of the late blight pathogen Phytophthora infestans can be explained by differential pathogenicity, the aggressiveness of isolates of the pathogen collected in France from potato and tomato was measured on detached leaflets of potato (cv. Bintje) and tomato (cv. Marmande). A preliminary trial with four isolates (two each from potato and tomato) showed that lesion appearance and development were similar for each isolate in detached leaflets and in whole plant tests in growth cabinets. Isolates collected from tomato were more pathogenic to tomato than isolates collected from potato. This was particularly the case for isolates belonging to the $\mathrm{A} 2$ mating type. Isolates originating from potato had a higher infection efficiency and a higher sporulation capacity on this
\end{abstract}

host, but they induced lesions that generally spread more slowly than those caused by isolates from tomato. Extensive variation for components of aggressiveness on potato, and to a lesser extent on tomato, was observed in collections of isolates from each of the two hosts. Competition experiments between one potato isolate and one tomato isolate in field plots of the susceptible potato cv. Bintje clearly demonstrated the higher competitive fitness of the potato isolate on its host of origin. Therefore, differential pathogenicity to potato and tomato certainly contributes to the differentiation between $P$. infestans populations present on potato and tomato in France; however, additional factors, possibly related to survival ability or random genetic drift, are probably also involved and may explain the persistence of weakly pathogenic isolates in these populations.

Additional keywords: Lycopersicum esculentum, population structure, Solanum tuberosum.
The status of host specificity in Phytophthora infestans has been a matter of debate ever since this destructive fungus was identified as the cause of potato, but also of tomato, late blight. P. infestans is known to be pathogenic to at least 40 species of the family Solanaceae (28), and host specificity may have led to a speciation event between $P$. infestans and $P$. mirabilis, two species with mutually exclusive host ranges, but morphologically indistinguishable (7) and giving rise to fertile hybrids (9). P. mirabilis is, thus, considered to be either a forma specialis of $P$. infestans (18) or a valid species (9).

Most investigations on species specificity within the fungus have dealt with its two hosts of major agricultural importance, potato (Solanum tuberosum) and tomato (Lycopersicum esculentum). Recent work using neutral markers (allozyme genotypes and nuclear DNA fingerprints) both in America $(8,19)$ and in Europe $(12,13)$ has shown that the genotypic compositions of $P$. infestans populations are different on tomato and potato. Furthermore, isolates present on tomato generally belong to simpler races (as determined with the set of potato differential cultivars possessing the R1 to R11 genes derived from $S$. demissum) than those collected on potato $(4,12)$. Many studies have also shown some degree of pathogenic specialization to potato or tomato of individual isolates of $P$. infestans, although no clear-cut separation into formae speciales specific to one or the other host could be observed. Interestingly, this preferential but nonexclusive pathogenic adaptation was observed both in 'old' populations of the fungus $(2,21)$, presumed to be a single clonal lineage, as well as in 'new' populations (15), derived from separate migrations from the center of diversity of the pathogen in central Mexico. Indeed, in the United States, vari-

Corresponding author: D. Andrivon; E-mail address: andrivon@rennes.inra.fr

Publication no. P-1999-0526-01R

(C) 1999 The American Phytopathological Society ous studies on tomato (15) and on potato (11) revealed differences in aggressiveness between isolates belonging to the major clonal lineages recovered in the field.

These data suggest that differences in pathogenicity might explain the host-related distribution of genotypes in $P$. infestans. This hypothesis has important implications for disease control strategies. If true, it implies that the separation between genotypes found preferentially on one or the other host is likely to persist over time and to limit gene flow, leading the practitioner to consider the two hostrelated groups as two independent populations that should be managed separately. Conversely, if the observed distribution of genotypes according to host is not related to pathogenicity traits, the current situation might be transient, and late blight management should simultaneously include populations present on both hosts. However, the validity of this hypothesis has so far not been convincingly demonstrated, because (i) only a few isolates have been tested simultaneously on both hosts and (ii) few attempts have been made to validate tests of aggressiveness performed on detached leaflets in vitro at the level of the whole plant or of the field plot.

Our goal in this study was, therefore, to test the hypothesis that the host-related distribution of $P$. infestans genotypes in France was a consequence of differential pathogenicity of the isolates to potato and tomato. Since testing a large number of isolates for aggressiveness on whole plants is difficult because of the considerable amount of space and plant material required, the first objective of this work was, therefore, to design and validate a testing methodology applicable to quantitative measurements of parameters of aggressiveness in large collections of isolates, but also representative of the progression of the disease on whole plants. A second objective was to quantify, using a collection of representative isolates collected from either potato or tomato, the components of pathogenicity (infection efficiency [IE], lesion expansion, and sporulation intensity $[\mathrm{SI}])$ on both potato and tomato. A third objec- 
tive was to assess the competitive fitness (i.e., the relative epidemic development) of a pair of isolates, one from potato and one from tomato, on potato under field conditions.

\section{MATERIALS AND METHODS}

$\boldsymbol{P}$. infestans isolates. Blighted plant material was collected in 1995 and 1996 by officers of the French Plant Protection Service in the two most important potato production areas in France, Brittany and northern France, and was sent by mail or brought directly to the laboratory for isolation. Most samples were obtained during survey tours of naturally infected potato fields, but some were also obtained from potato and tomato plants grown in private gardens and from tomato in commercial glasshouses (Table 1).

The 44 isolates retained for the tests of aggressiveness (Table 1) were chosen among a collection of 265 isolates obtained during 1995 and 1996 that were previously characterized for mating type, response to metalaxyl, virulence patterns, glucose phosphate isomerase (Gpi-1, EC 5.3.1.9) and peptidase (Pep-1, EC 3.4.3.1) allozyme genotypes, and mitochondrial (mt) DNA haplotypes (14). Isolates were selected to represent the various phenotypes, genotypes, and origins (sampling sites and types of stands: commercial crops, gardens, greenhouses, volunteers, and breeding plots) present in the complete collection. The isolates included 16 isolates collected on tomato and 28 isolates collected on potato. Thirty-eight isolates were of the A1 mating type and six of the A2 mating type. All isolates except one showed allozyme genotypes (Gpi 90/100 or Gpi 100/100, Pep 83/100 or Pep 100/100) and mtDNA haplotypes (Ia and IIa) characteristic of the 'new' population described in Europe by Spielman et al. (22). The exception (Table 1) was one isolate collected from potato in South Africa in 1995 that showed characteristics of the former European populations (Gpi 86/100, Pep 92/100; mtDNA Ib).

TABLE 1. Origin, genotypic, and phenotypic characteristics of Phytophthora infestans isolates used in pathogenicity tests

\begin{tabular}{|c|c|c|c|c|c|c|c|c|c|c|c|c|c|c|}
\hline \multirow{2}{*}{ Isolate } & \multirow{2}{*}{$\begin{array}{l}\text { Number in } \\
\text { collection }\end{array}$} & \multirow[b]{2}{*}{ Origin $^{\mathrm{x}}$} & \multirow{2}{*}{$\begin{array}{l}\text { Mating } \\
\text { type }\end{array}$} & \multirow{2}{*}{$\begin{array}{c}\text { Metalaxyl } \\
\text { sensitivity }\end{array}$} & \multicolumn{5}{|c|}{ Virulence } & \multirow[b]{2}{*}{$G p i$} & \multirow[b]{2}{*}{ Pep } & \multirow{2}{*}{$\begin{array}{l}\text { Mitochondrial } \\
\text { haplotype }\end{array}$} & \multicolumn{2}{|c|}{ Aggressiveness tested on } \\
\hline & & & & & $\overline{12}$ & 345 & 67 & 10 & $\overline{11}$ & & & & Potato & Tomato \\
\hline \multicolumn{15}{|c|}{$\overline{\text { From tomato }}$} \\
\hline \multicolumn{15}{|c|}{1995} \\
\hline 1 & 122.95 & $62 \mathrm{G}$ & $\mathrm{A} 2$ & $\mathrm{~S}$ & 1 & 4 & & & & $90 / 100$ & $100 / 100$ & IIa & + & \\
\hline 2 & 123.95 & $62 \mathrm{G}$ & A1 & $\mathrm{S}$ & 1 & 34 & 7 & 10 & 11 & $90 / 100$ & $100 / 100$ & $\mathrm{Ia}$ & + & \\
\hline 3 & 124.95 & $62 \mathrm{G}$ & $\mathrm{A} 2$ & $\mathrm{~S}$ & 1 & 4 & & & & $100 / 100$ & $100 / 100$ & IIa & + & \\
\hline \multicolumn{15}{|l|}{1996} \\
\hline 4 & 48.96 & $29 \mathrm{C}$ & A1 & I & 1 & 34 & 7 & & 11 & $100 / 100$ & $100 / 100$ & Ia & + & + \\
\hline 5 & 50.96 & $29 \mathrm{C}$ & A1 & $\mathrm{S}$ & 1 & 34 & 7 & 10 & 11 & $90 / 100$ & $83 / 100$ & Ia & & + \\
\hline 6 & $164 a .96$ & $62 \mathrm{C}$ & $\mathrm{A} 2$ & $\mathrm{~S}$ & 1 & 34 & 7 & & & $100 / 100$ & $100 / 100$ & IIa & + & + \\
\hline 7 & 166a.96 & $62 \mathrm{G}$ & A1 & $\mathrm{S}$ & 1 & 34 & 7 & & & $100 / 100$ & $100 / 100$ & Ia & + & \\
\hline 8 & 166b.96 & $62 \mathrm{G}$ & A1 & $\mathrm{S}$ & 1 & 34 & 7 & & & $100 / 100$ & $100 / 100$ & Ia & + & \\
\hline 9 & $167 \mathrm{a} .96$ & $62 \mathrm{G}$ & A1 & $\mathrm{S}$ & 1 & 34 & 7 & & & $100 / 100$ & $100 / 100$ & Ia & + & + \\
\hline 10 & $167 b .96$ & $62 \mathrm{G}$ & A1 & $\mathrm{S}$ & 1 & 34 & 7 & & & $100 / 100$ & $100 / 100$ & Ia & & + \\
\hline 11 & 168a.96 & $62 \mathrm{G}$ & A1 & $\mathrm{S}$ & 1 & 34 & 7 & & & $100 / 100$ & $100 / 100$ & Ia & + & + \\
\hline 12 & $168 b .96$ & $62 \mathrm{G}$ & A1 & $\mathrm{S}$ & 1 & 34 & 7 & & & $100 / 100$ & $100 / 100$ & Ia & + & + \\
\hline 13 & 179b.96 & $29 \mathrm{G}$ & A2 & nd & 1 & 34 & 7 & & & $90 / 100$ & $83 / 100$ & Ia & + & + \\
\hline 14 & 192.96 & $62 \mathrm{G}$ & A1 & nd & 1 & 34 & & & & $100 / 100$ & $100 / 100$ & Ia & + & + \\
\hline 15 & 197.96 & $62 \mathrm{G}$ & A1 & nd & 1 & 4 & & & & $100 / 100$ & $100 / 100$ & IIa & + & + \\
\hline 16 & 199.96 & $62 \mathrm{G}$ & A1 & nd & 1 & 34 & 7 & & & $100 / 100$ & $100 / 100$ & Ia & + & + \\
\hline \multicolumn{15}{|c|}{ From potato } \\
\hline \multicolumn{15}{|c|}{1995} \\
\hline 17 & 57.95 & $22 \mathrm{C}$ & A1 & $\mathrm{S}$ & 1 & 34 & 7 & 10 & 11 & $90 / 100$ & $83 / 100$ & Ia & + & \\
\hline 18 & 73.95 & $62 \mathrm{C}$ & A1 & $\mathrm{S}$ & 1 & 34 & 7 & 10 & 11 & $90 / 100$ & $83 / 100$ & Ia & + & \\
\hline 19 & 113.95 & $35 \mathrm{~V}$ & A1 & $\mathrm{S}$ & 1 & 4 & & 10 & 11 & $100 / 100$ & $100 / 100$ & IIa & + & \\
\hline 20 & 114.95 & $29 \mathrm{~V}$ & A1 & $\mathrm{S}$ & 1 & 34 & 7 & 10 & 11 & $90 / 100$ & $83 / 100$ & Ia & + & \\
\hline 21 & 135.95 & $62 \mathrm{C}$ & A1 & $\mathrm{S}$ & 1 & & 7 & 10 & 11 & $90 / 100$ & $100 / 100$ & Ia & + & \\
\hline 22 & 147.95 & $29 \mathrm{C}$ & A1 & $\mathrm{S}$ & 1 & 34 & & 10 & 11 & $90 / 100$ & $100 / 100$ & IIa & + & \\
\hline 23 & 151.95 & $29 \mathrm{C}$ & A1 & $\mathrm{S}$ & 1 & 4 & & & & $100 / 100$ & $100 / 100$ & IIa & + & \\
\hline 24 & 153.95 & $29 \mathrm{C}$ & A1 & $\mathrm{S}$ & 1 & 34 & 7 & & 11 & $100 / 100$ & $100 / 100$ & IIa & + & \\
\hline 25 & 166.95 & $\mathrm{AfS}^{\mathrm{z}} \mathrm{C}$ & A1 & nd & 1 & 4 & & & & $86 / 100$ & $100 / 100$ & $\mathrm{Ib}$ & + & \\
\hline \multicolumn{15}{|l|}{1996} \\
\hline 26 & 54.96 & $22 \mathrm{C}$ & A1 & $\mathrm{S}$ & 1 & 34 & 7 & 10 & 11 & $90 / 100$ & $83 / 100$ & Ia & + & + \\
\hline 27 & 65.96 & $22 \mathrm{C}$ & A1 & $\mathrm{S}$ & 1 & 34 & 7 & 10 & 11 & $90 / 100$ & $83 / 100$ & $\mathrm{Ia}$ & & + \\
\hline 28 & 86b.96 & $29 \mathrm{~B}$ & A1 & $\mathrm{S}$ & 1 & 34 & 7 & 10 & 11 & $90 / 100$ & $83 / 100$ & Ia & + & + \\
\hline 29 & 90b.96 & $29 \mathrm{~B}$ & A1 & $\mathrm{R}$ & nd & & & & & $90 / 100$ & $83 / 100$ & Ia & + & + \\
\hline 30 & $92 a .96$ & $29 \mathrm{~B}$ & A1 & I & 1 & 34 & 7 & & 11 & $90 / 100$ & $83 / 100$ & Ia & + & + \\
\hline 31 & 106.96 & $29 \mathrm{~B}$ & A1 & $\mathrm{S}$ & 1 & 34 & & & & $90 / 100$ & $83 / 100$ & Ia & & + \\
\hline 32 & 141a.96 & $29 \mathrm{~B}$ & A1 & $\mathrm{S}$ & 1 & 34 & 6 & & & $90 / 100$ & $100 / 100$ & nd & + & + \\
\hline 33 & 146.96 & $29 \mathrm{~B}$ & A1 & I & nd & & & & & $90 / 100$ & $83 / 100$ & nd & + & + \\
\hline 34 & 147a.96 & $29 \mathrm{~B}$ & A1 & $\mathrm{S}$ & 12 & 34 & 67 & 10 & 11 & $100 / 100$ & $100 / 100$ & nd & + & + \\
\hline 35 & 153.96 & $62 \mathrm{C}$ & A1 & nd & 1 & 34 & 7 & & & $90 / 100$ & $83 / 100$ & Ia & + & + \\
\hline 36 & $158 \mathrm{~d} .96$ & $29 \mathrm{~B}$ & A1 & $\mathrm{S}$ & 12 & 34 & 67 & & & $90 / 100$ & $100 / 100$ & IIa & + & \\
\hline 37 & 165.96 & $62 \mathrm{G}$ & $\mathrm{A} 2$ & $\mathrm{~S}$ & 1 & 34 & 7 & & & nd & nd & nd & & + \\
\hline 38 & 203.96 & $62 \mathrm{C}$ & A1 & nd & 1 & 34 & 7 & 10 & 11 & $90 / 100$ & $83 / 100$ & $\mathrm{Ia}$ & & + \\
\hline 39 & 210.96 & $60 \mathrm{C}$ & A1 & nd & 1 & 34 & 7 & & 11 & $90 / 100$ & $83 / 100$ & $\mathrm{Ia}$ & + & \\
\hline 40 & 207.96 & $62 \mathrm{C}$ & A2 & nd & 1 & 4 & 7 & & & $90 / 100$ & $83 / 100$ & Ia & + & \\
\hline 41 & 208.96 & $60 \mathrm{~V}$ & A1 & nd & 1 & 34 & & & & $100 / 100$ & $100 / 100$ & Ia & + & \\
\hline 42 & 209.96 & $62 \mathrm{G}$ & A1 & nd & nd & & & & & $90 / 100$ & $83 / 100$ & $\mathrm{Ia}$ & + & \\
\hline 43 & 225.96 & $62 \mathrm{C}$ & A1 & nd & nd & & & & & nd & nd & nd & + & \\
\hline 44 & 226.96 & $62 \mathrm{C}$ & A1 & nd & nd & & & & & nd & nd & nd & + & \\
\hline
\end{tabular}

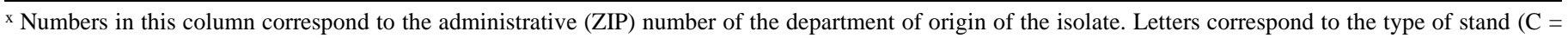
commercial crop, $\mathrm{G}=$ garden, $\mathrm{B}=$ breeding nursery, and $\mathrm{V}=$ volunteers).

y $\mathrm{S}=$ sensitive, $\mathrm{I}=$ intermediate, $\mathrm{R}=$ resistant, and $\mathrm{nd}=$ not determined.

${ }^{\mathrm{z}}$ AfS $=$ South Africa. 
All isolates were maintained on $10 \%$ clarified V8 agar medium at $18^{\circ} \mathrm{C}$ during characterization and tests. Most were stored in liquid nitrogen for long-term preservation. Sporangial suspensions were prepared by gently scraping the surface of 20-day-old cultures in sterile water and adjusting the concentration to $10^{4}$ sporangia per $\mathrm{ml}$ with a hemacytometer.

Plant material. Seed tubers of potato cv. Bintje and seeds of tomato cv. Marmande were obtained from commercial suppliers. Plants were grown in a glasshouse in plastic pots $(17 \mathrm{~cm}$ diameter) filled with a mixture in equal proportions of soil, sand, and peat. The glasshouse was maintained at a mean daily temperature of 20 to $22^{\circ} \mathrm{C}$. Natural daylight was supplemented with artificial light from 250-W high pressure sodium lamps to obtain a 16-h day/8-h night photoperiod.

Assessments for aggressiveness under controlled conditions. Design and validation of a detached-leaf assay. Four isolates (two from tomato, isolates 1 and 3, and two from potato, isolates 18 and 23) (Table 1) with different phenotypic and genotypic characteristics
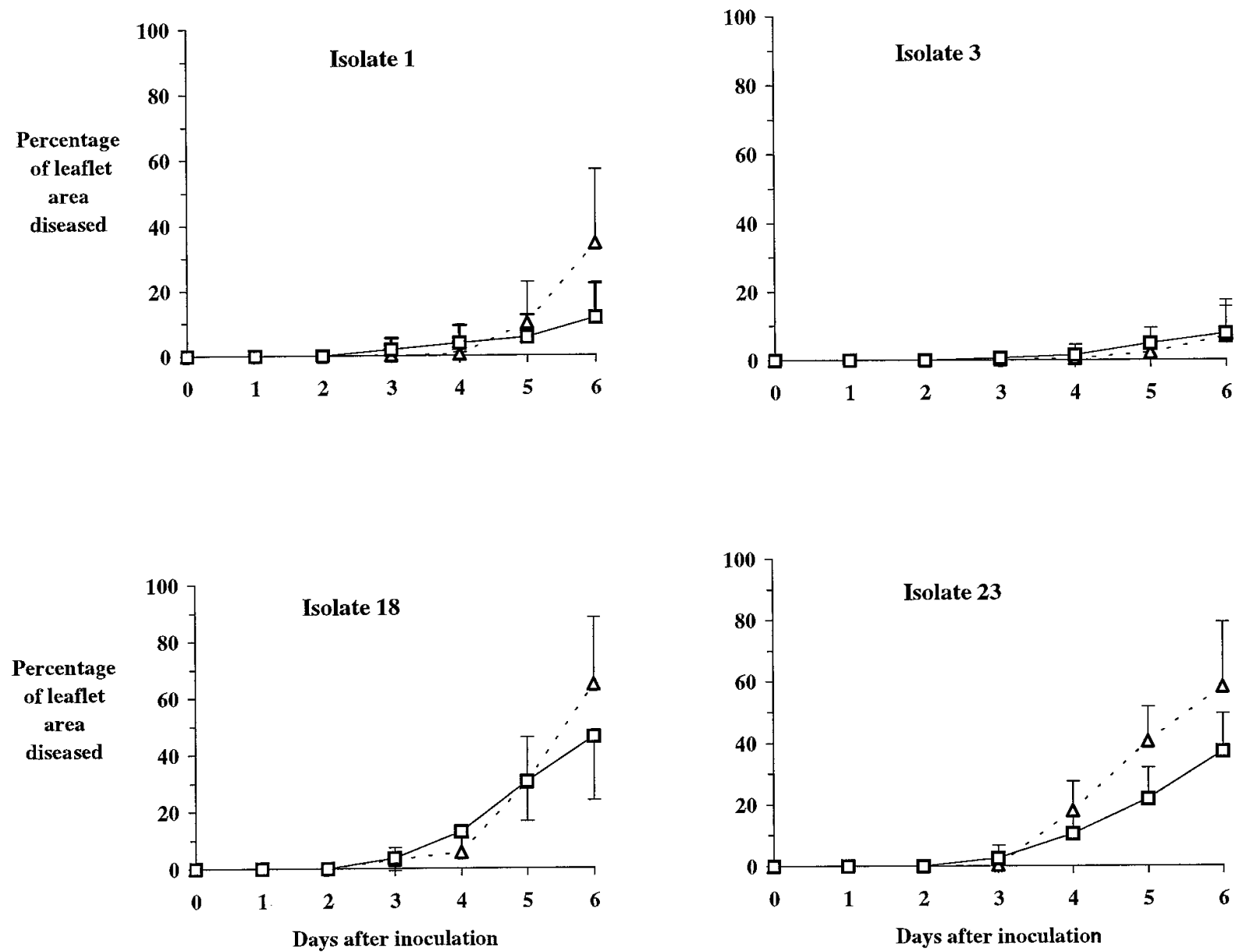

Fig. 1. Comparison of lesion development after inoculation of potato leaflets left attached to entire plants (squares) or detached and kept in vitro (triangles) with four isolates of Phytophthora infestans (isolates 18 and 23 from potato and isolates 1 and 3 from tomato). Indicated are mean diseased areas calculated from 30 inoculated sites. Error bars correspond to half the standard deviations of the means; to facilitate reading, they are indicated as either positive or negative errors.

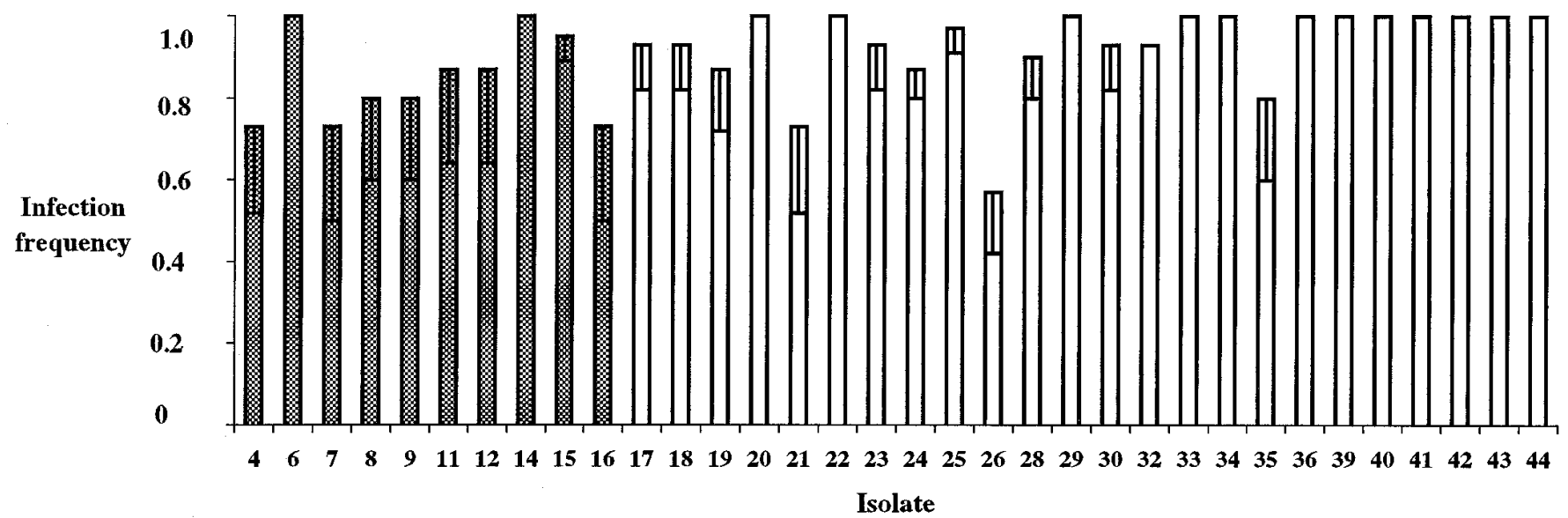

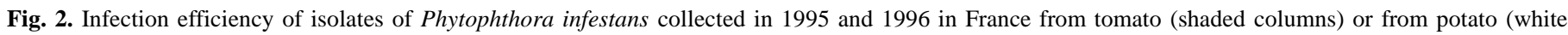

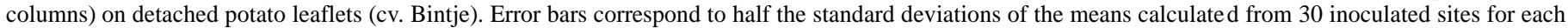
isolate; to facilitate reading, they are indicated as negative errors. 
were tested on both entire potato plants and detached potato leaves of the highly susceptible cv. Bintje to compare the two methods for assessing aggressiveness. Fifteen leaflets, randomly distributed on whole plants grown as previously described for 6 to 7 weeks, were each inoculated with two $25-\mu$ droplets of a sporangial suspension. For each leaflet inoculated, one drop of the inoculum suspension was deposited on either side of the main vein. Only one isolate was inoculated onto a given plant. Infected plants, covered with plastic bags previously sprayed with water on the inner surface, were incubated for 6 days in climate chambers regulated at $18^{\circ} \mathrm{C}$ and 16 -h day length. In parallel, entire leaves were detached from 6- to 7-week-old potato plants and deposited on moist filter paper in transparent plastic boxes. Each of the five leaflets of each leaf was inoculated with two $25-\mu$ l droplets of a sporangial suspension of a single isolate, deposited on each side of the main vein. Infected leaves were incubated in transparent plastic boxes in climate chambers for 6 days at $18^{\circ} \mathrm{C}$ and 16-h day length. To prevent petioles from drying and to enhance fungal development, a high relative humidity was maintained in the plastic boxes throughout the experiments by adding water as required to the filter paper.

In both trials (inoculations on whole plants and on detached leaves), each infection site (half leaflet) was scored separately, and each isolate was tested on three replicate leaves. On each infected leaflet (both on whole plants and on detached leaves), the lesion size (LS) was assessed visually each day for 6 days after inoculation as the proportion of the half leaflet showing late blight symptoms.

Measurement of parameters of aggressiveness. The detached-leaf protocol described above was used to measure three components of aggressiveness: IE, lesion growth, and SI. Of the 44 isolates, 23 isolates were tested for aggressiveness on tomato and 38 on potato; 17 were tested on both hosts (Table 1). Tests on tomato were performed on leaves detached from plants of the susceptible cv. Marmande and grown for 9 to 10 weeks in the greenhouse under the same conditions used for potato.

IE was calculated as the proportion of inoculated sites that developed lesions, on three replicate leaves per isolate. LS, estimated visually as the proportion of the half-leaflet area diseased,

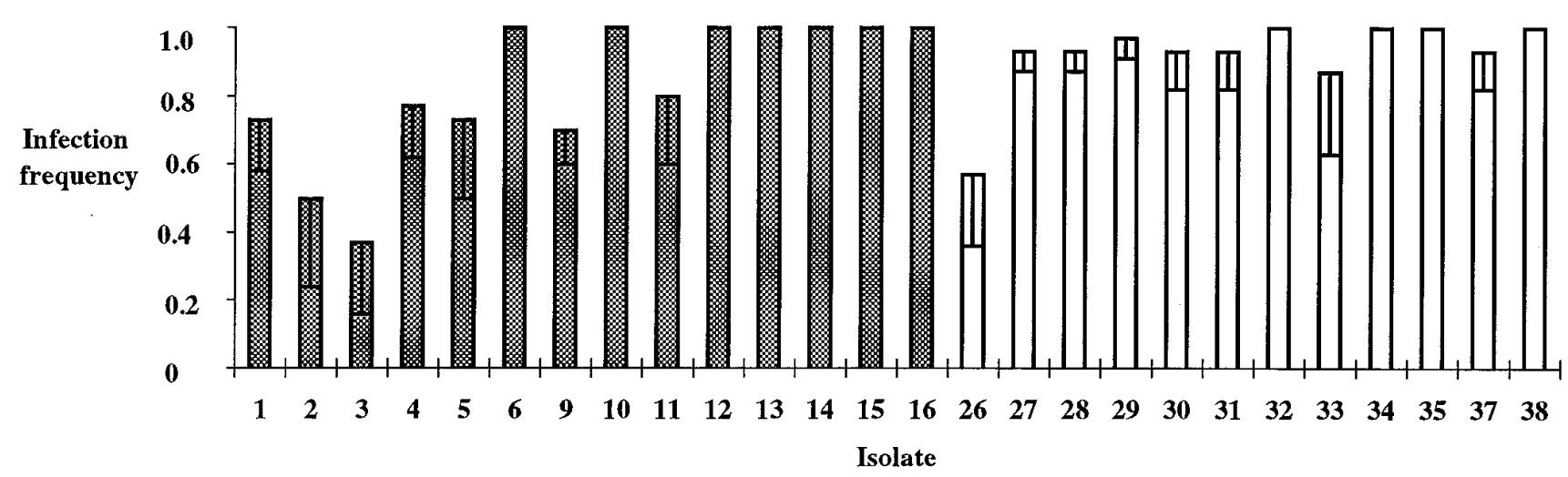

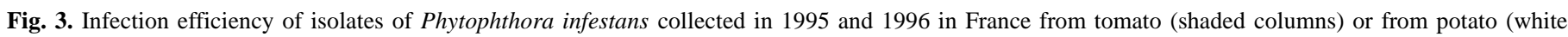

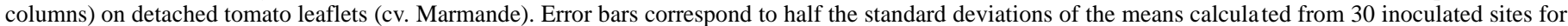
each isolate; to facilitate reading, they are indicated as negative errors.

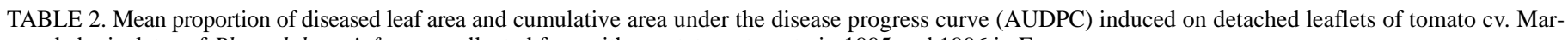
mande by isolates of Phytophthora infestans collected from either potato or tomato in 1995 and 1996 in France

\begin{tabular}{|c|c|c|c|c|c|c|c|c|c|}
\hline \multicolumn{8}{|c|}{ Day after inoculation } & \multirow[b]{3}{*}{ Isolate } & \multirow[b]{3}{*}{ AUDPC } \\
\hline \multicolumn{2}{|r|}{3} & \multicolumn{2}{|r|}{4} & \multicolumn{2}{|r|}{5} & \multicolumn{2}{|r|}{6} & & \\
\hline Isolate & $\begin{array}{c}\text { Percentage of } \\
\text { diseased leaf area }\end{array}$ & Isolate & $\begin{array}{c}\text { Percentage of } \\
\text { diseased leaf area }\end{array}$ & Isolate & $\begin{array}{c}\text { Percentage of } \\
\text { diseased leaf area }\end{array}$ & Isolate & $\begin{array}{c}\text { Percentage of } \\
\text { diseased leaf area }\end{array}$ & & \\
\hline $13^{x, y}$ & $15.7 \mathrm{a}^{\mathrm{z}}$ & $15^{y}$ & $62.4 \mathrm{a}^{\mathrm{z}}$ & $15^{y}$ & $98.7 \mathrm{a}^{\mathrm{z}}$ & $15^{y}$ & $100.0 \mathrm{a}^{\mathrm{z}}$ & $15^{y}$ & $211.2 \mathrm{a}^{\mathrm{z}}$ \\
\hline $16^{y}$ & $12.4 \mathrm{~b}$ & $16^{y}$ & $55.0 \mathrm{~b}$ & $6^{x, y}$ & $81.0 \mathrm{~b}$ & $6^{\mathrm{x}, \mathrm{y}}$ & $100.0 \mathrm{a}$ & $16^{y}$ & $189.2 \mathrm{~b}$ \\
\hline $37^{x}$ & $10.0 \mathrm{c}$ & $13^{\mathrm{x}, \mathrm{y}}$ & $34.0 \mathrm{c}$ & $16^{\mathrm{y}}$ & $81.0 \mathrm{~b}$ & $11^{\mathrm{y}}$ & $100.0 \mathrm{a}$ & $6^{x, y}$ & $157.4 \mathrm{c}$ \\
\hline 38 & $8.5 \mathrm{~cd}$ & $37^{x}$ & $30.7 \mathrm{~cd}$ & $11^{\mathrm{y}}$ & $72.9 \mathrm{c}$ & $16^{y}$ & $94.0 \mathrm{ab}$ & $13^{x, y}$ & $143.4 \mathrm{~cd}$ \\
\hline 29 & $7.0 \mathrm{de}$ & $6^{x, y}$ & $26.1 \mathrm{~d}$ & $37^{x}$ & $62.1 \mathrm{~d}$ & $13^{x, y}$ & $91.7 \mathrm{ab}$ & $37^{x}$ & $142.5 \mathrm{~cd}$ \\
\hline 35 & $6.6 \mathrm{de}$ & $10^{y}$ & $17.7 \mathrm{e}$ & $13^{x, y}$ & $55.7 \mathrm{de}$ & $37^{x}$ & $89.3 \mathrm{a}-\mathrm{c}$ & $11^{y}$ & $139.3 \mathrm{~d}$ \\
\hline 33 & $5.3 \mathrm{e}$ & 38 & $16.7 \mathrm{ef}$ & $10^{y}$ & $53.3 \mathrm{e}$ & $4^{y}$ & $83.8 \mathrm{bc}$ & $10^{y}$ & $111.4 \mathrm{e}$ \\
\hline 30 & $2.2 \mathrm{f}$ & $11^{\mathrm{y}}$ & $16.2 \mathrm{e}-\mathrm{g}$ & $4^{y}$ & $35.8 \mathrm{f}$ & $10^{y}$ & $80.7 \mathrm{c}$ & $4^{y}$ & $94.0 \mathrm{f}$ \\
\hline 34 & $1.9 \mathrm{f}$ & $4^{y}$ & $15.8 \mathrm{e}-\mathrm{h}$ & $14^{y}$ & $34.8 \mathrm{f}$ & $5^{y}$ & $80.0 \mathrm{c}$ & $5^{y}$ & $85.0 \mathrm{fg}$ \\
\hline 28 & $1.8 \mathrm{f}$ & 29 & $15.8 \mathrm{e}-\mathrm{h}$ & $5^{y}$ & $32.3 \mathrm{fg}$ & $14^{y}$ & $67.4 \mathrm{~d}$ & $14^{y}$ & $76.5 \mathrm{gh}$ \\
\hline 32 & $1.3 \mathrm{f}$ & 34 & $14.7 \mathrm{e}-\mathrm{h}$ & 34 & $31.8 \mathrm{fg}$ & $12^{y}$ & $59.0 \mathrm{e}$ & 34 & $68.4 \mathrm{hi}$ \\
\hline 27 & $1.1 \mathrm{f}$ & $5^{y}$ & $12.7 \mathrm{e}-\mathrm{i}$ & 33 & $25.7 \mathrm{gh}$ & 34 & $42.1 \mathrm{f}$ & 38 & $62.8 \mathrm{~h}-\mathrm{j}$ \\
\hline $4^{y}$ & $1.0 \mathrm{f}$ & 33 & $12.0 \mathrm{e}-\mathrm{i}$ & 38 & $25.0 \mathrm{~g}-\mathrm{i}$ & $9^{y}$ & $40.9 \mathrm{f}$ & 29 & $57.1 \mathrm{i}-\mathrm{k}$ \\
\hline $14^{y}$ & $0.7 \mathrm{f}$ & 35 & $9.8 \mathrm{e}-\mathrm{i}$ & 29 & $24.7 \mathrm{~g}-\mathrm{i}$ & 38 & $33.7 \mathrm{fg}$ & 33 & $56.7 \mathrm{i}-\mathrm{k}$ \\
\hline 31 & $0.6 \mathrm{f}$ & $9^{y}$ & $9.2 \mathrm{e}-\mathrm{i}$ & $9^{y}$ & $23.8 \mathrm{~g}-\mathrm{j}$ & 33 & $32.6 \mathrm{f}-\mathrm{h}$ & $9^{y}$ & $53.7 \mathrm{i}-1$ \\
\hline $12^{y}$ & $0.6 \mathrm{f}$ & 28 & $8.8 \mathrm{f}-\mathrm{i}$ & 30 & $22.2 \mathrm{~h}-\mathrm{j}$ & 26 & $28.9 \mathrm{gh}$ & $12^{y}$ & $49.2 \mathrm{j}-1$ \\
\hline $6^{x, y}$ & $0.5 \mathrm{f}$ & 30 & $8.1 \mathrm{f}-\mathrm{i}$ & 26 & $19.5 \mathrm{~h}-\mathrm{j}$ & 32 & $28.3 \mathrm{gh}$ & 35 & $44.1 \mathrm{j}-\mathrm{m}$ \\
\hline $9^{y}$ & $0.4 \mathrm{f}$ & $14^{y}$ & $7.7 \mathrm{~g}-\mathrm{i}$ & 35 & $19.0 \mathrm{~h}-\mathrm{j}$ & 29 & $26.0 \mathrm{gh}$ & 30 & $43.9 \mathrm{j}-\mathrm{m}$ \\
\hline $15^{y}$ & $0.3 \mathrm{f}$ & 27 & $7.1 \mathrm{hi}$ & 28 & $17.5 \mathrm{~h}-\mathrm{j}$ & 30 & $25.2 \mathrm{gh}$ & 26 & $38.8 \mathrm{k}-\mathrm{m}$ \\
\hline $10^{y}$ & $0.1 \mathrm{f}$ & 32 & $5.4 \mathrm{i}$ & 32 & $17.1 \mathrm{~h}-\mathrm{j}$ & 35 & $24.0 \mathrm{gh}$ & 28 & $37.6 \mathrm{k}-\mathrm{m}$ \\
\hline 26 & $0.1 \mathrm{f}$ & 26 & $4.8 \mathrm{i}$ & 27 & $16.1 \mathrm{~h}-\mathrm{j}$ & 28 & $20.7 \mathrm{~h}$ & 32 & $37.4 \mathrm{k}-\mathrm{m}$ \\
\hline $11^{\mathrm{y}}$ & $0.1 \mathrm{f}$ & $12^{y}$ & $4.5 \mathrm{i}$ & $12^{y}$ & $14.9 \mathrm{ij}$ & 31 & $20.4 \mathrm{~h}$ & 27 & $33.9 \mathrm{~lm}$ \\
\hline $5^{y}$ & $0.1 \mathrm{f}$ & 31 & $4.3 \mathrm{i}$ & 31 & $13.9 \mathrm{j}$ & 27 & $20.4 \mathrm{~h}$ & 31 & $28.8 \mathrm{~m}$ \\
\hline
\end{tabular}

$\mathrm{x}$ A2 isolate.

y Isolate from tomato.

${ }^{\mathrm{z}}$ In each column, means followed by the same letter are not significantly different (Student-Newman-Keuls test, $P=0.05$ ). 
was scored daily for 6 days after inoculation. LS data were analyzed statistically at each date and used to compute areas under the disease progress curves (AUDPC). AUDPC were used concurrently with LS at each date because of the different rankings of isolates on a given host at successive dates. SI was assessed as the number of sporangia produced per unit of lesion area 8 days after inoculation. It was measured, on potato, for seven isolates collected from potato and three isolates collected from tomato. To perform this measurement, sporangia were washed from lesions with $10 \mathrm{ml}$ of demineralized water and counted under a microscope on 10 aliquots of the resulting suspensions using a hemacytometer. The lesion surface was calculated from LS data and the total surface of each leaflet, measured with a planimeter (Area Measurement System; Delta-T Devices Ltd., Burwell, United Kingdom).

IE and LS were measured for all isolates tested, while SI was measured on isolates from the 1995 sampling (isolates 1 to 3 and 17 to 25) (Table 1) only. IE, LS, and AUDPC data were subjected to analysis of variance using the general linear models module of the SAS software package (SAS Institute, Cary, NC). When significant effects were detected, means were compared with the Student-Newman-Keuls test.

Competitive fitness in the field. Experimental field plots were established in 1995 at two locations in Brittany (western France), Le Rheu and Romillé. At Le Rheu, the plot consisted of 14 rows of 15 plants, while at Romillé, the plot was 10 rows of 20 plants. At both locations, elite seed tubers of potato cv. Bintje were planted at spacings of $30 \mathrm{~cm}$ within the row and $75 \mathrm{~cm}$ between rows. Both plots were artificially inoculated with two isolates, one from tomato (isolate 2) and one from potato (isolate 18). These two strains were chosen because they could be easily differentiated at the Pep-1 locus, isolate 2 being Pep 100/100 and isolate 18 being Pep 83/100 (Table 1). Inoculation of the plots was performed by depositing plants of potato cv. Bintje, previously inoculated by spraying a sporangial suspension of the corresponding isolates and bearing sporulating lesions, at selected points within the plots. At Le Rheu, each isolate was deposited on two separate points, located opposite to one another in the diagonal of the plot. At Romillé, only one site was infected with each isolate; the two sites were located opposite to one another on the western side of the plot. Sprinkler irrigation was used at both locations to favor disease development.

After inoculation, disease severity on each plant in the two plots was estimated at two different dates using a 0 to 7 scale, in which $0=$ no lesions, $1=$ one to five infected leaflets, $2=5$ to 10 infected leaflets, $3=$ over 10 infected leaflets and lesions covering less than $25 \%$ plant area, $4=$ lesions covering 25 to $50 \%$ plant area, $5=$ lesions covering 50 to $75 \%$ plant area, $6=$ lesions covering 75 to $90 \%$ plant area, and $7=$ lesions covering $>90 \%$ plant area. Furthermore, at each scoring date, an infected leaflet was

TABLE 3. Mean percentage of diseased leaf area and cumulative area under the disease progress curve (AUDPC) induced on detached leaflets of potato cv. Bintje by isolates of Phytophthora infestans collected from either potato or tomato in 1995 and 1996 in France

\begin{tabular}{|c|c|c|c|c|c|c|c|c|c|}
\hline \multicolumn{8}{|c|}{ Day after inoculation } & \multirow[b]{3}{*}{ Isolate } & \multirow[b]{3}{*}{ AUDPC } \\
\hline \multicolumn{2}{|r|}{3} & \multicolumn{2}{|r|}{4} & \multicolumn{2}{|r|}{5} & \multicolumn{2}{|r|}{6} & & \\
\hline Isolate & $\begin{array}{c}\text { Percentage of } \\
\text { diseased leaf area }\end{array}$ & Isolate & $\begin{array}{c}\text { Percentage of } \\
\text { diseased leaf area }\end{array}$ & Isolate & $\begin{array}{c}\text { Percentage of } \\
\text { diseased leaf area }\end{array}$ & Isolate & $\begin{array}{c}\text { Percentage of } \\
\text { diseased leaf area }\end{array}$ & & \\
\hline $7^{w}$ & $7.2 \mathrm{a}^{\mathrm{x}}$ & 39 & $32.3 \mathrm{a}^{\mathrm{x}}$ & 39 & $71.0 \mathrm{a}^{\mathrm{x}}$ & 39 & $89.3 \mathrm{a}^{\mathrm{x}}$ & 39 & $148.8 \mathrm{a}^{\mathrm{x}}$ \\
\hline $11^{\mathrm{w}}$ & $4.0 \mathrm{~b}$ & $7^{w}$ & $23.1 \mathrm{~b}$ & 33 & $63.4 \mathrm{ab}$ & 44 & $87.7 \mathrm{ab}$ & 33 & $120.9 \mathrm{~b}$ \\
\hline $14^{\mathrm{w}}$ & $3.8 \mathrm{~b}$ & $8^{w}$ & $21.2 \mathrm{bc}$ & 42 & $57.3 \mathrm{bc}$ & 33 & $87.6 \mathrm{ab}$ & 42 & $117.5 \mathrm{~b}$ \\
\hline $16^{\mathrm{w}}$ & $3.7 \mathrm{~b}$ & 42 & $18.3 \mathrm{~b}-\mathrm{d}$ & 44 & $50.3 \mathrm{~cd}$ & 42 & $82.7 \mathrm{a}-\mathrm{c}$ & $7^{w}$ & $113.8 \mathrm{bc}$ \\
\hline $15^{\mathrm{w}}$ & $3.6 \mathrm{~b}$ & 23 & $18.0 \mathrm{~b}-\mathrm{d}$ & $7^{w}$ & $49.1 \mathrm{~cd}$ & $16^{\mathrm{w}}$ & $80.0 \mathrm{a}-\mathrm{d}$ & 44 & $109.4 b-d$ \\
\hline $6^{\mathrm{w}, \mathrm{y}}$ & $3.5 \mathrm{~b}$ & $16^{\mathrm{w}}$ & $16.7 \mathrm{c}-\mathrm{e}$ & $15^{\mathrm{w}}$ & $47.7 \mathrm{c}-\mathrm{e}$ & $7^{w}$ & $75.9 \mathrm{a}-\mathrm{e}$ & $15^{\mathrm{w}}$ & $101.6 \mathrm{~b}-\mathrm{e}$ \\
\hline 18 & $3.0 \mathrm{bc}$ & $15^{\mathrm{w}}$ & $15.3 \mathrm{de}$ & $8^{w}$ & $43.7 \mathrm{c}-\mathrm{f}$ & 36 & $75.8 \mathrm{a}-\mathrm{e}$ & $8^{w}$ & $101.0 \mathrm{~b}-\mathrm{e}$ \\
\hline $8^{w}$ & $2.8 \mathrm{~b}-\mathrm{d}$ & $11^{\mathrm{w}}$ & $15.2 \mathrm{de}$ & $16^{\mathrm{w}}$ & $40.4 \mathrm{~d}-\mathrm{g}$ & $15^{\mathrm{w}}$ & $73.8 \mathrm{a}-\mathrm{f}$ & $16^{\mathrm{w}}$ & $98.9 \mathrm{~b}-\mathrm{e}$ \\
\hline $12^{\mathrm{w}}$ & $2.7 \mathrm{~b}-\mathrm{e}$ & $6^{\mathrm{w}, \mathrm{y}}$ & $15.0 \mathrm{de}$ & 41 & $40.3 \mathrm{~d}-\mathrm{g}$ & $9^{w}$ & $73.2 \mathrm{a}-\mathrm{f}$ & $11^{\mathrm{w}}$ & $91.4 \mathrm{c}-\mathrm{f}$ \\
\hline 39 & $1.6 \mathrm{c}-\mathrm{f}$ & 44 & $14.8 \mathrm{~d}-\mathrm{f}$ & $9^{w}$ & $40.3 \mathrm{~d}-\mathrm{g}$ & 41 & $72.0 \mathrm{a}-\mathrm{f}$ & 41 & $87.2 \mathrm{~d}-\mathrm{f}$ \\
\hline 42 & $1.0 \mathrm{~d}-\mathrm{f}$ & 33 & $13.2 \mathrm{~d}-\mathrm{g}$ & $11^{\mathrm{w}}$ & $39.6 \mathrm{~d}-\mathrm{g}$ & $12^{\mathrm{w}}$ & $71.2 \mathrm{a}-\mathrm{f}$ & 23 & $86.2 \mathrm{~d}-\mathrm{g}$ \\
\hline 41 & $1.0 \mathrm{~d}-\mathrm{f}$ & $14^{w}$ & $12.6 \mathrm{~d}-\mathrm{h}$ & 23 & $38.9 \mathrm{~d}-\mathrm{g}$ & 29 & $70.0 \mathrm{a}-\mathrm{f}$ & $6^{\mathrm{w}, \mathrm{y}}$ & $83.0 \mathrm{e}-\mathrm{g}$ \\
\hline 17 & $0.9 \mathrm{~d}-\mathrm{f}$ & $12^{\mathrm{w}}$ & $12.5 \mathrm{~d}-\mathrm{h}$ & $6^{w, y}$ & $35.0 \mathrm{~d}-\mathrm{h}$ & $8^{w}$ & $69.2 \mathrm{~b}-\mathrm{g}$ & $12^{\mathrm{w}}$ & $79.5 \mathrm{e}-\mathrm{h}$ \\
\hline 44 & $0.9 \mathrm{~d}-\mathrm{f}$ & 41 & $10.4 \mathrm{e}-\mathrm{i}$ & 29 & $32.4 \mathrm{e}-\mathrm{i}$ & $11^{\mathrm{w}}$ & $68.9 \mathrm{~b}-\mathrm{g}$ & $9^{w}$ & $78.2 \mathrm{e}-\mathrm{h}$ \\
\hline 33 & $0.8 \mathrm{~d}-\mathrm{f}$ & 29 & $8.9 \mathrm{f}-\mathrm{j}$ & 36 & $30.4 \mathrm{f}-\mathrm{j}$ & 18 & $64.6 \mathrm{c}-\mathrm{h}$ & 29 & $76.5 \mathrm{e}-\mathrm{h}$ \\
\hline $9^{w}$ & $0.8 \mathrm{~d}-\mathrm{f}$ & 22 & $8.8 \mathrm{f}-\mathrm{j}$ & $12^{\mathrm{w}}$ & $30.0 \mathrm{f}-\mathrm{j}$ & $6^{\mathrm{w}, \mathrm{y}}$ & $62.5 \mathrm{~d}-\mathrm{h}$ & 36 & $72.0 \mathrm{f}-\mathrm{i}$ \\
\hline $4^{w}$ & $0.8 \mathrm{~d}-\mathrm{f}$ & 20 & $8.1 \mathrm{~g}-\mathrm{k}$ & 18 & $29.0 \mathrm{f}-\mathrm{k}$ & 43 & $62.2 \mathrm{~d}-\mathrm{h}$ & 18 & $69.7 \mathrm{f}-\mathrm{i}$ \\
\hline $40^{y}$ & $0.8 \mathrm{~d}-\mathrm{f}$ & 19 & $7.1 \mathrm{~g}-1$ & 43 & $29.0 \mathrm{f}-\mathrm{k}$ & $40^{y}$ & $61.0 \mathrm{~d}-\mathrm{h}$ & $14^{\mathrm{w}}$ & $67.1 \mathrm{f}-\mathrm{j}$ \\
\hline 22 & $0.7 \mathrm{~d}-\mathrm{f}$ & 18 & $6.8 \mathrm{~h}-1$ & 24 & $27.2 \mathrm{f}-1$ & 24 & $58.8 \mathrm{e}-\mathrm{i}$ & 43 & $65.5 \mathrm{f}-\mathrm{j}$ \\
\hline 36 & $0.6 \mathrm{~d}-\mathrm{f}$ & $4^{w}$ & $6.1 \mathrm{i}-1$ & 19 & $25.6 \mathrm{~g}-1$ & 23 & $58.3 \mathrm{e}-\mathrm{i}$ & 24 & $60.0 \mathrm{~g}-\mathrm{k}$ \\
\hline 34 & $0.6 \mathrm{~d}-\mathrm{f}$ & 43 & $5.2 \mathrm{i}-1$ & $14^{\mathrm{w}, \mathrm{y}}$ & $25.0 \mathrm{~g}-1$ & $14^{\mathrm{w}}$ & $55.3 \mathrm{e}-\mathrm{j}$ & 19 & $56.4 \mathrm{~h}-1$ \\
\hline 35 & $0.5 \mathrm{~d}-\mathrm{f}$ & 36 & $3.3 \mathrm{j}-1$ & 17 & $22.1 \mathrm{~h}-\mathrm{m}$ & 19 & $54.8 \mathrm{f}-\mathrm{j}$ & 22 & $49.3 \mathrm{i}-\mathrm{m}$ \\
\hline 26 & $0.5 \mathrm{~d}-\mathrm{f}$ & 24 & $3.3 \mathrm{j}-1$ & 21 & $21.6 \mathrm{~h}-\mathrm{m}$ & $25^{z}$ & $50.0 \mathrm{~g}-\mathrm{k}$ & 21 & $46.8 \mathrm{i}-\mathrm{m}$ \\
\hline 21 & $0.5 \mathrm{~d}-\mathrm{f}$ & 19 & $3.3 \mathrm{j}-1$ & 22 & $19.1 \mathrm{~h}-\mathrm{n}$ & 32 & $47.9 \mathrm{~h}-1$ & 32 & $43.0 \mathrm{j}-\mathrm{m}$ \\
\hline 20 & $0.4 \mathrm{~d}-\mathrm{f}$ & $40^{y}$ & $2.8 \mathrm{j}-1$ & 32 & $18.3 \mathrm{i}-\mathrm{o}$ & 34 & $42.3 \mathrm{i}-1$ & $40^{y}$ & $42.4 \mathrm{j}-\mathrm{m}$ \\
\hline 32 & $0.4 \mathrm{~d}-\mathrm{f}$ & $2^{w}$ & $2.1 \mathrm{kl}$ & 20 & $15.0 \mathrm{j}-\mathrm{o}$ & 28 & $42.2 \mathrm{i}-1$ & 17 & $39.9 \mathrm{k}-\mathrm{n}$ \\
\hline 23 & $0.4 \mathrm{~d}-\mathrm{f}$ & 35 & 1.11 & $2^{w}$ & $14.4 \mathrm{j}-\mathrm{O}$ & $1^{\mathrm{w}, \mathrm{y}}$ & $40.0 \mathrm{j}-\mathrm{m}$ & $4^{w}$ & $35.4 \mathrm{k}-\mathrm{O}$ \\
\hline 29 & $0.3 \mathrm{ef}$ & 17 & 0.91 & $4^{w}$ & $12.8 \mathrm{k}-\mathrm{O}$ & 21 & $33.7 \mathrm{k}-\mathrm{n}$ & $25^{z}$ & $34.5 \mathrm{k}-\mathrm{p}$ \\
\hline 43 & 0.3 ef & $9^{w}$ & 0.91 & $1^{\mathrm{w}, \mathrm{y}}$ & $11.91-\mathrm{O}$ & 17 & $32.9 \mathrm{k}-\mathrm{n}$ & 20 & $33.11-\mathrm{p}$ \\
\hline 30 & 0.3 ef & 34 & 0.81 & $25^{z}$ & $9.1 \mathrm{~m}-\mathrm{o}$ & $4^{w}$ & $32.3 \mathrm{k}-\mathrm{n}$ & $1^{\mathrm{w}, \mathrm{y}}$ & $32.51-\mathrm{p}$ \\
\hline $3^{\mathrm{w}, \mathrm{y}}$ & 0.2 ef & $3^{w, y}$ & 0.61 & $40^{y}$ & $8.7 \mathrm{~m}-\mathrm{o}$ & $2^{w}$ & $30.01-\mathrm{n}$ & $2^{w}$ & $31.61-\mathrm{p}$ \\
\hline $2^{w}$ & 0.2 ef & 32 & 0.61 & 28 & $6.4 \mathrm{~m}-\mathrm{O}$ & 34 & $22.8 \mathrm{~m}-\mathrm{O}$ & 28 & $28.0 \mathrm{~m}-\mathrm{q}$ \\
\hline 24 & 0.2 ef & $1^{\mathrm{w}, \mathrm{y}}$ & 0.61 & 35 & 4.0 no & 20 & 21.7 no & 34 & $15.6 \mathrm{n}-\mathrm{q}$ \\
\hline 19 & $0.2 \mathrm{ef}$ & 26 & 0.61 & 30 & 3.2 no & 35 & $13.6 \mathrm{o}$ & 35 & $12.2 \mathrm{o}-\mathrm{q}$ \\
\hline $1^{\mathrm{w}, \mathrm{y}}$ & $0.1 \mathrm{f}$ & 28 & 0.51 & 34 & 3.0 no & 30 & $11.1 \mathrm{o}$ & 30 & $9.4 \mathrm{pq}$ \\
\hline $25^{z}$ & $0.1 \mathrm{f}$ & 30 & 0.51 & $3^{w, y}$ & $2.3 \mathrm{o}$ & 26 & $7.6 \mathrm{o}$ & 26 & $6.6 \mathrm{q}$ \\
\hline 28 & $0.1 \mathrm{f}$ & $25^{z}$ & 0.41 & 26 & $2.0 \mathrm{o}$ & $3^{\mathrm{w}, \mathrm{y}}$ & $6.5 \mathrm{o}$ & $3^{\mathrm{w}, \mathrm{y}}$ & $6.3 \mathrm{q}$ \\
\hline
\end{tabular}

${ }^{\mathrm{w}}$ Isolate from tomato.

${ }^{x}$ In each column, means followed by the same letter are not significantly different (Student-Newman-Keuls test, $P=0.05$ ).

y A2 isolate.

${ }^{\mathrm{z}}$ Isolate from South Africa. 
collected from each infected plant. The pathogen was isolated and characterized for Pep-1 phenotype as described elsewhere (14).

\section{RESULTS}

Validation of the detached-leaflet bioassay. For each of the four isolates tested, disease development was similar on inoculated leaflets of potato cv. Bintje kept in vitro or left attached to the mother plant (Fig. 1). As a rule, symptoms appeared earlier on whole plants than on the detached leaflets, but subsequent disease progression was generally faster on the detached leaflets. Disease development was significantly faster $(P<0.05)$ with the two potato isolates 18 and 23 than with the two tomato isolates, although minor variations in rankings within each group occurred between dates (data not shown).

Measurement of parameters of aggressiveness. IE. Average IE on potato was significantly lower $(P<0.05)$ for isolates collected from tomato $(0.79)$ than for those collected from potato (0.92), despite significant variation among isolates from each host (Fig. 2). On tomato, no significant difference was found between the two hosts of origin, although significant variation occurred among individual isolates. This variation was greater among isolates from tomato than among isolates from potato (Fig. 3).

Lesion expansion. Lesion expansion on both potato and tomato was significantly faster in isolates collected from tomato than in isolates collected from potato at all dates $(F>68.92, P<0.001)$ (Tables 2 and 3), except 3 days after inoculation on tomato in which isolates from potato were significantly more pathogenic than those from tomato $(F=14.63, P<0.001)$. The same conclusions could be reached when AUDPC values were analyzed instead of severity values at each scoring date $(F>31.32, P<0.001)$. Variation among isolates from a given host was much greater on potato, in which isolates collected from tomato and from potato were scattered across the whole range of pathogenicity, than on tomato, in which isolates collected on this host were consistently the most pathogenic (Tables 2 and 3). Interestingly, isolates belonging to the A2 mating type were among the most pathogenic on tomato but among the least pathogenic on potato.

SI. Large variations were observed among isolates from each host, but the three isolates from tomato sporulated, on average, significantly less on potato $(P<0.05)$ than the seven isolates from potato (Fig. 4).

Competitive fitness in the field. Disease progressed rapidly in both field plots of potato cv. Bintje after infected spreader plants were deposited (Fig. 5A and B). The epidemic was more severe at Le Rheu than at Romillé, possibly because four infection sites instead of two were used at this site. In both cases, all isolates recovered from the newly infected plants had the same Pep-1 genotype (83/100) as isolate 18, originating from potato; isolates with the Pep-1

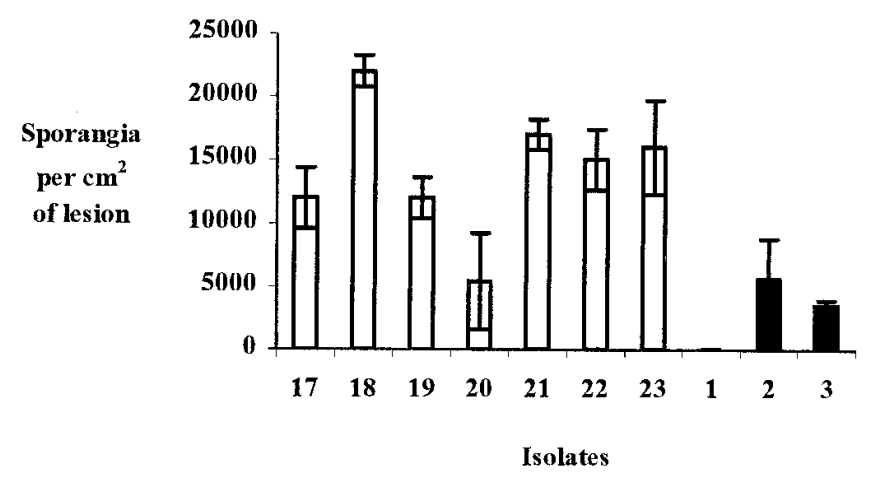

Fig. 4. Spore production per unit of lesion area measured 8 days after inoculation on detached potato leaflets (cv. Bintje) of 10 isolates of Phytophthora infestans collected from potato (white bars) or from tomato (dark bars) in 1995. Error bars correspond to the standard deviations of the means calculated from all the lesions developing from 30 inoculated sites for each isolate. genotype $100 / 100$, identical to that of isolate 2 , were restricted to the plants inoculated with this isolate (Fig. 5A and B).

\section{DISCUSSION}

Although a number of workers have favored detached-leaf assays for quantitative assessments of fitness parameters in $P$. infestans $(3,10,11,15,16,27)$, few direct attempts have been made to compare data gathered from inoculations on detached plant parts with those on whole plants on a given set of isolates. In this context, the good concordance between lesion development in detached leaflets and in whole plants for the four isolates tested with both conditions is of interest, since it validates a commonly used, miniaturized protocol for testing components of aggressiveness on extended collections of isolates. It complements the evidence available from previous studies, basically qualitative, showing that detached-leaf assays are valid for screening resistance sources or for identifying race-specific resistance genes (24-26).

From the in vitro measurements, lesions induced on tomato by isolates from tomato expanded faster than those caused by isolates collected from potato. This finding is consistent with previous reports, both in 'old' and 'new' populations of $P$. infestans $(2,15,19$, 21 ), and supports the view that some specificity to tomato exists within $P$. infestans worldwide, despite the differences in genotypic constitution of the populations of the pathogen. The situation appears, however, less clear-cut when aggressiveness to potato is considered. Indeed, despite a lower IE, lesions induced by isolates collected from tomato spread, on average, faster on potato leaflets than those caused by isolates originating from potato. Nevertheless, the isolates with the fastest lesion growth and the highest spore production on potato were from this host. Furthermore, considerable variation was observed within each collection for lesion development, IE, and sporulation capacity. These observations, which are consistent with previous reports in American $(9,11,16)$ and in European populations of the pathogen $(3,6)$, indicate that a range of fitness can be found among isolates collected from a single host.

This conclusion has implications in terms of explanation of population structures of $P$. infestans in Europe, but also in terms of epidemiology and disease management. As far as population structures are concerned, our results indicate that pathogenic adaptation is a likely explanation for the distribution of $P$. infestans genotypes on tomato, in which isolates most pathogenic on this host predominate. They also provide clues about the discrepancies in mating-type frequencies between the two hosts. A2 isolates consistently ranked among the most pathogenic on tomato but among the least pathogenic on potato. Specific adaptation to tomato may, thus, explain the higher frequency of the A2 mating type on tomato in France $(12,13)$ and maybe also in gardens (where tomatoes are usually grown alongside potatoes) compared with commercial potato crops elsewhere in Europe (5). Interestingly, many of these isolates (such as isolates 1, 3, 6, and 13) (Table 1) have characteristics (A2, Gpi 100/100) identical to those of isolate 466 of Miller et al. (16), which also displayed a very low aggressiveness to potato.

However, pathogenic adaptation is not sufficient to explain the distribution of $P$. infestans genotypes on potato, at least if lesion growth is considered as the major component of aggressiveness, since several isolates collected from potato proved less fit on this host than isolates from tomato according to this criterion. Two hypotheses may be formulated to resolve this apparent contradiction. First, lesion growth alone is probably not a representative measure of aggressiveness. It can, indeed, be supposed that IE and sporulation capacity are major parameters in the determination of the epidemic potential of an isolate, since they determine the amount of secondary inoculum produced and the number of lesions resulting from this production. Spielman et al. (23) found that AUDPC measurements in the field correlated best with sporulation capacity, a trait for which potato isolates consistently outperformed tomato isolates when measured on potato leaflets. This finding is in 

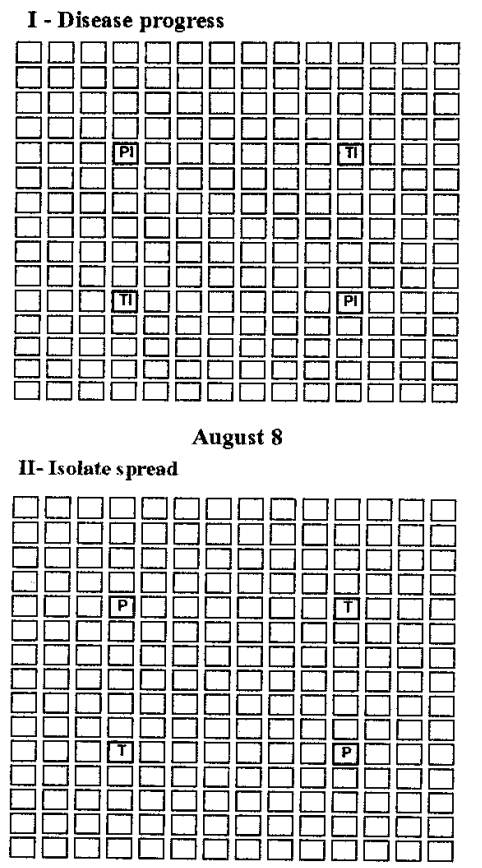

August 8

B

I- Disease progress

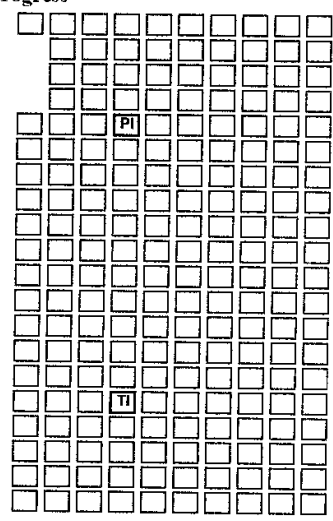

August 10

II- Isolate spread

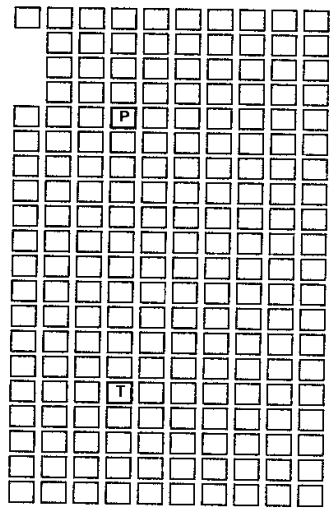

Angust 10

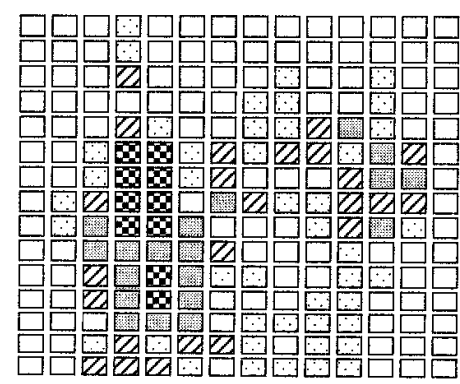

August 12

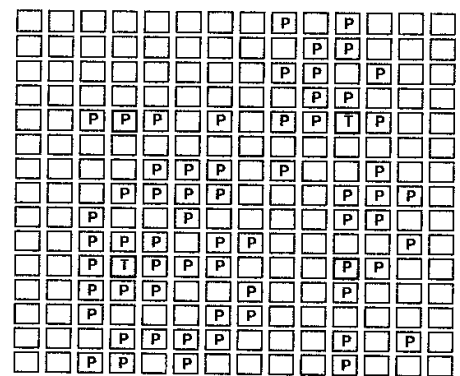

August 13

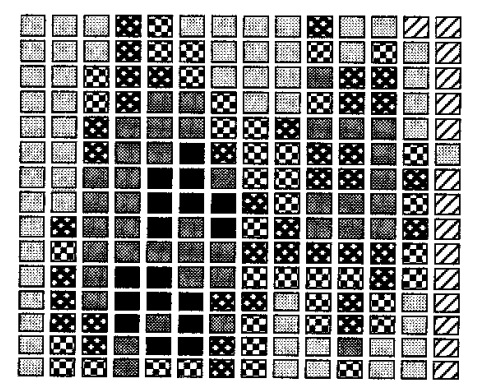

Angust 16

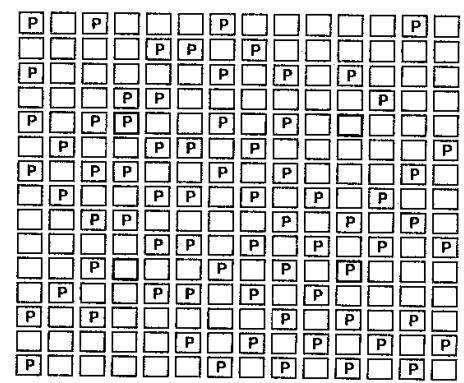

August 17

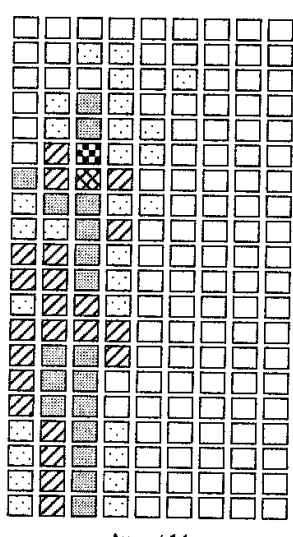

August 14

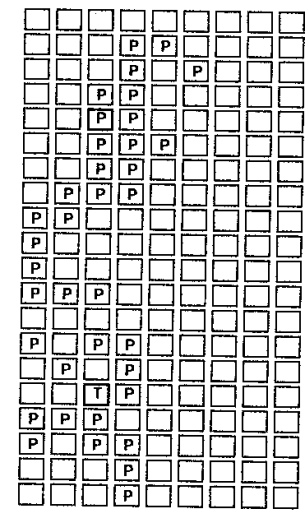

August 16
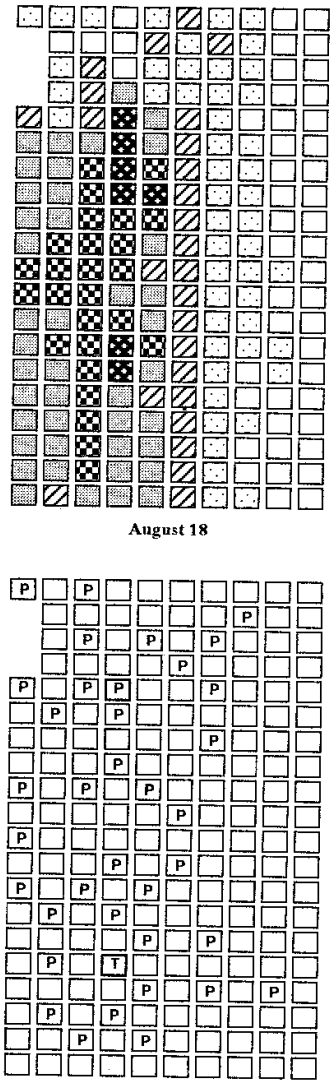

August 19

\begin{tabular}{|c|c|c|c|}
\hline $\begin{array}{l}\text { no lesion } \\
25-50 \% \text { foliage diseased }\end{array}$ & $\begin{array}{l}\because 1-5 \text { leaflets infected } \\
\$ 50-75 \% \text { foliage diseased }\end{array}$ & $\begin{array}{l}\text { W/ 5-10 leaflets infected } \\
75-90 \% \text { foliage diseased }\end{array}$ & $\begin{array}{l}>10 \text { leaflets infected with }<25 \% \text { of foliage area diseased } \\
>90 \% \text { foliage diseased }\end{array}$ \\
\hline
\end{tabular}

Fig. 5. Spatial and temporal evolution of late blight in two plots, A, Le Rheu, and B, Romillé, artificially inoculated with Phytophthora infestans isolate 18, collected from potato, and isolate 2, collected from tomato, in 1995. The location of plants infected with isolate 18 and isolate 2 are indicated as PI and TI, respectively. I, Disease development followed in the two plots (each box represents a single plant) according to eight severity categories. II, Isolate spread from the sources of inoculum, monitored with a phenotypic marker (Pep-1 genotypes): $\mathrm{P}=$ isolate with the same Pep genotype as isolate 18; and T = isolate with the same Pep genotype as isolate 2 . 
line with our observation of a greater epidemic potential of isolate 18 compared with isolate 2 in field potato plots, which is consistent with the relative sporulation of these two isolates on detached potato leaves.

Various authors $(3,23)$ devised a composite fitness index by simply multiplying the three components of aggressiveness (IE, LS, and sporulation capacity). Spielman et al. (23) attempted to validate this index by correlating it with AUDPC values recorded in field experiments, but used only one set of field assessments and based their work on isolates collected over a span of several years and kept in storage. We chose not to compute such a composite index because it is difficult to accurately estimate the weight of each component to obtain an estimate of aggressiveness representative to the actual fitness of the isolate in the field. The determination of the proper weighting factors to be included in a composite index formula would require that the epidemic potential of a number of isolates be measured in the field, possibly in a way similar to the one used in our field experiments, and be used to validate formulas generated through modeling.

The presence of a range of isolates, including some with a low apparent aggressiveness, within $P$. infestans collections from potato could also result from differences in survival abilities. Since $P$. infestans is a poor saprophyte (1), its populations undergo drastic demographic bottlenecks when the hosts are absent (5). In such situations, balanced pathogenicity to several hosts is beneficial in the long term, since it increases the possibility for the pathogen to switch hosts and hence reduce the effects of an unfavorable period in its life cycle. Differential survival abilities may also be related to differences in response to climatic factors, particularly temperature, for which there is some evidence that variation exists among $P$. infestans isolates $(17,20)$. The coming challenge is now to quantify this variation in collections of isolates well characterized for genotypic constitution and pathogenicity to potato and tomato, to model its epidemiological consequences for both pathogenicity and survival ability, and to integrate both phases of the life cycle into a global description of the fitness interactions between isolates to explain population structures. This information is required to propose management strategies of late blight that encompass the populations actually involved in inciting the disease on each host.

\section{LITERATURE CITED}

1. Andrivon, D. 1995. Biology, ecology, and epidemiology of the potato late blight pathogen Phytophthora infestans in soil. Phytopathology 85: 1053-1056.

2. Berg, A. 1926. Tomato late blight and its relation to late blight of potato. W. Va. Agric. Exp. Stn. Bull. 205.

3. Day, J. P., and Shattock, R. C. 1997. Aggressiveness and other factors relating to displacement of populations of Phytophthora infestans in England and Wales. Eur. J. Plant Pathol. 103:379-391.

4. Deahl, K. L., Inglis, D. A., and deMuth, S. P. 1993. Testing for resistance to metalaxyl in Phytophthora infestans from northwestern Washington. Am. Potato J. 70:779-795.

5. Drenth, A., Tas, I. C. Q., and Govers, F. 1994. DNA fingerprinting uncovers a new sexually reproducing population of Phytophthora infestans in the Netherlands. Eur. J. Plant Pathol. 100:97-107.

6. Flier, W. G., and Turkensteen, L. J. 1996. Aggressiveness of the new established population of Phytophthora infestans in the Netherlands. EAPR (Eur. Assoc. Potato Res.) Abstr. Conf. Pap. 13:598.
7. Galindo, A.-J., and Hohl, H. R. 1985. Phytophthora mirabilis, a new species of Phytophthora. Sydowia 38:87-96.

8. Goodwin, S. B., Cohen, B. A., Deahl, K. L., and Fry, W. E. 1994. Migration from northern Mexico as the probable cause of recent genetic changes in populations of Phytophthora infestans in the United States and Canada. Phytopathology 84:553-558.

9. Goodwin, S. B., and Fry, W. E. 1994. Genetic analyses of interspecific hybrids between Phytophthora infestans and Phytophthora mirabilis. Exp. Mycol. 18:20-32.

10. Goodwin, S. B., Sujkowski, L. S., and Fry, W. E. 1995. Rapid evolution of pathogenicity within clonal lineages of the potato late blight disease fungus. Phytopathology 85:669-676.

11. Kato, M., Mizubuti, E. S., Goodwin, S. B., and Fry, W. E. 1997. Sensitivity to protectant fungicides and pathogenic fitness of clonal lineages of Phytophthora infestans in the United States. Phytopathology 87:973-978.

12. Lebreton, L., and Andrivon, D. 1998. French isolates of Phytophthora infestans from potato and tomato differ in phenotype and genotype. Eur. J. Plant Pathol. 104:583-594.

13. Lebreton, L., Duvauchelle, S., and Andrivon, D. 1996. Occurrence in France and Belgium of A2 mating type isolates of Phytophthora infestans in 1995. EAPR (Eur. Assoc. Potato Res.) Abstr. Conf. Pap. 13:262-263.

14. Lebreton, L., Laurent, C., and Andrivon, D. 1998. Evolution of Phytophthora infestans populations in the two most important potato production areas of France during 1992-1996. Plant Pathol. 47:427-439.

15. Legard, D. E., Lee, T. Y., and Fry, W. E. 1995. Pathogenic specialization in Phytophthora infestans: Aggressiveness on tomato. Phytopathology 85:1356-1361.

16. Miller, J. S., Johnson, D. A., and Hamm, P. B. 1998. Aggressiveness of isolates of Phytophthora infestans from the Columbia Basin of Washington and Oregon. Phytopathology 88:190-197.

17. Mizubuti, E. S. G., and Fry, W. E. 1998. Temperature effects on developmental stages of isolates from three clonal lineages of Phytophthora infestans. Phytopathology 88:837-843.

18. Möller, E. M., de Cock, A. W. A. M., and Prell, H. H. 1993. Mitochondrial and nuclear DNA restriction enzyme analysis of the closely related Phytophthora species $P$. infestans, P. mirabilis and P. phaseoli. J. Phytopathol. 139:309-321.

19. Oyarzun, P. J., Pozo, A., Ordoñez, M. E., Doucett, K., and Forbes, G. A. 1998. Host specificity of Phytophthora infestans on tomato and potato in Ecuador. Phytopathology 88:265-271.

20. Schepers, H. T. A. M. 1998. Epidemiological parameters in decision support systems for Phytophthora infestans. PAV Spec. Rep. 3:30-36.

21. Small, T. 1938. The relation between potato blight and tomato blight. Ann. Appl. Biol. 25:271-276.

22. Spielman, L. J., Drenth, A., Davidse, L. C., Sujkowski, L. J., Gu, W., Tooley, P. W., and Fry, W. E. 1991. A second world-wide migration and population displacement of Phytophthora infestans? Plant Pathol. 40: 422-430.

23. Spielman, L. J., McMaster, B. J., and Fry, W. E. 1992. Relationships between measurements of fitness and disease severity in Phytophthora infestans. Plant Pathol. 41:317-324.

24. Stewart, H. E. 1990. Effect of plant age and inoculum concentration on expression of major gene resistance to Phytophthora infestans in detached potato leaflets. Mycol. Res. 94:823-826.

25. Swiezynski, K. M., Sieczka, M. T., Sujkowski, L. S., Zarzycka, H., and Zimnoch-Guzowska, E. 1991. Resistance to Phytophthora infestans in potato genotypes originating from wild species. Plant Breed. 107:28-38.

26. Tooley, P. W. 1990. Variation in resistance to Phytophthora infestans among 21 Solanum verrucosum plant introductions. Am. Potato J. 67: 491-498.

27. Tooley, P. W., Sweigard, J. A., and Fry, W. E. 1986. Fitness and virulence of Phytophthora infestans isolates from sexual and asexual populations. Phytopathology 76:1209-1212.

28. Turkensteen, L. J. 1978. Phytophthora infestans: Three new hosts and a specialized form causing a foliar blight of Solanum muricatum in Peru. Plant Dis. Rep. 62:829. 